\title{
Editorial dossiê "Investigação preliminar, meios ocultos e novas tecnologias"
}

\author{
Editorial dossier "Preliminary inquiry, hidden mechanisms \\ and new technology"
}

\section{Manuel Monteiro Guedes Valente ${ }^{1}$}

Professor da Universidade Autónoma de Lisboa/Portugal Doutor em Direito pela Universidade Católica Portuguesa Editor-associado deste dossiê da RBDPP manuelmonteirovalente@gmail.com

9 lattes.cnpq.br/4001544191185131

D orcid.org/0000-0002-4991-8707

O Direito processual penal é por excelência o Direito dos inocentes. Esta nossa aceção encontra-se em conflito permanente com a ânsia e o clamor de um povo que reclama justiça imediata e ou "a justiça do já". Esta dinâmica da sociedade internético-personocêntrica² derruba barreiras e limites, que se impuseram ao longo da história e que se devem impor como inultrapassáveis no campo da obtenção da prova penal, em especial no campo da investigação criminal stricto sensu, ou seja, aquela que se destina a recolher vestígios e indícios probatórios, elementos de prova reais e pessoais para o processo-crime para que, em sede de julgamento, se produza a prova fundante da decisão judicial.

A investigação criminal quer-se científica, metódica e integrante de um pensar de ser humano centro de toda a discussão produzida pela

1 Doutor em Direito pela Universidade Católica Portuguesa. Professor da Universidade Autónoma de Lisboa/Portugal. Professor Convidado do ISCPSI, da PUC-RS e da ESP/ANP-PF. Editor-associado deste dossiê da RBDPP. Of-Counsel da Rogério Alves \& Associados - Sociedade de Advogados.

2 Conceito por nós construído e apresentado no III Seminário do IBADPP: Democracia e Processo Penal. Cf. o nosso Os Desafios do Processo Penal do Estado Democrático de Direito: A Sociedade Internético-Personocêntrica. Disponível em: <http://www. ibadpp.com.br/category/artigosinternacionais>. Acesso em: 21 mai. 2017. 
ciência de modo a que mais do que objeto seja sujeito ativo e transformador de um mundo do tempo em constante passado. A opção por meios de investigação ou meios de obtenção de prova com uma dinâmica tecnológica, digital ou intra-social, assentes numa lógica de celeridade incontrolável e de negação do tempo da norma, que é substituído pela norma do tempo, é uma caraterística da justiça dos nossos dias. A investigação criminal, nas últimas duas décadas, passou a centralizar e esgotar o processo penal, centralizando toda a dinâmica e detonando a segurança jurídica e a segurança dogmática exigida pela legiferação e pela doutrina jurídico-criminal garantista e humanista.

O desejo de uma justiça célere e veloz, que satisfaça o clamor dos cidadãos, que se encontram em estado paneónico - medo esquizofrénico - perante os fenómenos da criminalidade económico-financeira [v. g., crimes tributários (fiscais e previdenciários), manipulação de mercado, corrupção, branqueamento], do crime organizado transnacional [v. g., crime de tráfico de armas, de droga, de seres humanos e de órgãos humanos] e do terrorismo, conduziram os decisores políticos a implementar meios de obtenção de prova especializados, especiais e excecionais: ampliação do âmbito das interceções telefónicas, registo de voz off e imagem, gravações ambientais, gravações e fotografias por meio de câmaras de videovigilância, agentes infiltrados física e digitalmente, rastreios e persecuções digitais, localizações celulares, controlo e monitoramento concreto de IP, IMEI e GPS, recurso a IMSI-Carther (IMEI), buscas e apreensões preventivas no sistema digital a nível nacional, regional e internacional sem qualquer conhecimento do visado, e a admissibilidade e utilização como meios de prova os relatórios elaborados pelos serviços secretos.

Mas a excecionalidade, inata e inerente às tipologias criminais em causa que justificam no campo dos princípios políticos e, em parte, filosófico-jurídicos, o recurso a estes meios de obtenção de prova excecionais, especializados e indispensáveis para a obtenção da prova e a descoberta da verdade processual, metamorfoseou-se em 'vulgaridade' de recurso, quer no âmbito material quer no âmbito processual. No âmbito material, o legislador e o intérprete têm ampliado os espaços de recurso quer de forma positiva em lei - aumentando o catálogo de crimes que admitem o recurso aos meios excecionais de investigação ou 
através do modelo causal ou modal de submissão do meio de obtenção de prova no campo das conexões operativas e pressupostos aferidos da própria norma [v. g., permitir o recurso a estes meios sempre que o crime base geral seja o de associação criminosa, o de organização criminosa ou o de grupo ou bando criminoso] - ou de forma hermenêutica e exegética - deixando ao intérprete e ao aplicador da norma restritiva e legitimante do meio oculto ou do meio excecional de obtenção de prova a subsunção da mesma a critérios concretos de concordância prática ou de conexões do tipo objetivo ou subjetivo ou a critérios de defesa da segurança e repressão ou eliminação dos estados de perigosidade.

A consciência de um mundo em constante mudança e de desafios dinâmicos ao Direito e à defesa do Estado constitucional democrático exigem-nos clareza e clarividência quanto às dificuldades existentes na persecução criminal - em especial na recolha e conservação da prova adequada a que se realize a justiça segundo uma verdade prática, processual, material e judicialmente válida no respeito pelos direitos e liberdades fundamentais de todos os cidadãos de modo a que se alcance e restabeleça a paz jurídica e social ${ }^{3}$ - e seriedade no tratamento dos temas objetivos e concretos da vida judiciário-criminal, que podem ou não promover uma sociedade mais justa, mais livre, mais solidária e mais humana ${ }^{4}$. Por essa razão, consideramos que o recurso a meios excecionais de investigação criminal ou a metodologias de obtenção de informação e prova criminal deve estar previsto e legislado, mas submetido desde logo ao princípio da excecionalidade. O que é excecional não é nem pode ser vulgar.

Esta aceção obriga-nos a avocar alguns dos princípios que devem reger o recurso aos meios excecionais de investigação ou de obtenção de prova: o princípio da reserva de Constituição na restrição e no recurso ao meio em concreto, assim como da reserva de lei que expressem de for-

3 Cf.: VAlENTE, Manuel M. G. Processo penal - Tomo I. 3. ${ }^{a}$ Edição. Coimbra: Almedina, 2010, p. 23-28; DIAS, Jorge de Figueiredo. Direito Processual Penal. Lições policopiadas por Maria João Antunes. Coimbra, 1988-9, p. 21-26; e ROXIN, Claus. Derecho Procesal Penal. Tradução do alemão Strafverfahrensrecht de Gabriela E. Córdoba e Daniel R. Pastor. Buenos Aires: Del Puerto s.r.l., 2000, p. 1-5.

4 Cf. artigo $1 .^{\circ}$ da Constituição da República Portuguesa e artigo $1 .^{\circ}$ da Constituição da República Federativa do Brasil. 
ma praeclara os fundamentos (pressupostos), fins e limites conformes à axiologia constitucional - materialidade axiológica e dimensão formal-procedimental e orgânica ${ }^{5}$-, não fosse o processo penal o "sismógrafo da Constituição do Estado"; o princípio do catálogo fechado dos crimes e dos meios ocultos de investigação [sem que se olvide a admissibilidade restritiva do modelo aberto, causal e modal se deles resultar a garantia mais efetiva dos direitos e liberdades fundamentais pessoais dos visados e dos intervenientes no processo produtivo de prova], de modo a retirar do espaço e tempo do intérprete e aplicador da lei [norma] amplitudes e admissibilidades incongruentes e inaceitável jus constitucionalmente; o princípio da reserva judicial ou de juiz, cuja decisão de autorização, por serem meios de elevada colisão com os direitos e liberdades e garantias fundamentais pessoais, é constitucionalmente da exclusiva competência do juiz; o princípio da proporcionalidade em sentido lato ou da proibição do excesso que se subdivide em três corolários diretos [adequação, necessidade e exigibilidade, e proporcionalidade em sentido estrito] e em dois indiretos [subsidiariedade e indispensabilidade], sem que se olvidem os pressupostos da irretroatividade e da proibição da negação do conteúdo nuclear do direito, da liberdade ou da garantia a restringir]; o princípio da fundamentação da decisão de autorização de recurso ao meio excecional de obtenção de prova, devendo a mesma ser epistemológica, teleológica e axiológica a decorrer em tempos e em espaços distintos: a montante [tempo e espaço da investigação criminal pela polícia, pelo Ministério Público e pelo Juiz das liberdades] e a jusante [tempo e espaço de controlo do meio pelo Juiz das liberdades e tempo e espaço da fase solene do devido processo legal que é o julgamento] $]^{7}$; o princípio $d a$

5 ANDRADE, Manuel da Costa. "Bruscamente no Verão Passado”, a Reforma do Código de processo penal. Observações críticas sobre uma lei que podia e devia ter sido diferente. Coimbra: Coimbra Editora, 2009, p. 112-199.

6 ROXIN, Claus. Derecho Procesal ..., p. 10. Como escrevera Tiedemann, o processo penal é o sismógrafo do tecido constitucional legítimo, válido, vigente e efetivo, encontrando-se nesse tecido um "limite extremo". Cf. TIEDEMANN, Klaus. O Direito Processual Penal - Terceira Parte. In: ROXIN, Claus; ARZT, Günther; TIEDEMANN, Klaus. Introdução ao Direito Penal e ao Direito Processual Penal. Tradução do alemão Einführung in das Strafrecht und Strafprozessrecht de Gercélia Batista de Oliveira Mendes. Belo Horizonte: Del Rey, 2007, p. 155.

7 A fundamentação das decisões judiciais funciona [deve funcionar] como crivo de transparência e manifestação de publicidade, e de fiscalização 
vinculação ao fim expresso no requerimento inicial e na solicitação do Ministério Público ao juiz competente de modo a que se evitem os pedidos de admissibilidade e valoração discricionária de conhecimentos fortuitos ou se utilizem meios de elevada danosidade social para investigar crimes que não os admitem ab initio como meios de obtenção de prova e/ou de investigação criminal.

Estes princípios regem ou devem reger a atuação da polícia criminal no âmbito das suas atribuições originárias ou delegadas na persecução das tipologias criminais que admitem o recurso a meios ocultos de investigação criminal, assim como devem reger a regulação do acesso e do uso das novas tecnologias para a persecução criminal tendo sempre em conta as dinâmicas opostas: a dinâmica da vítima, cuja ação de tutela se pode aferir de um princípio geral do Direito - v. g., princípio do estado de necessidade de intervenção do Estado - e dinâmica do agente do crime, cuja restrição anormal ou qualificada de direitos, liberdades e garantias fundamentais pessoais exigem uma maior conformidade positiva constitucional.

Os autores que escreveram para o dossiê abordam as questões supra identificadas e essenciais no âmbito do recurso aos meios excecionais ou ocultos de investigação criminal, trazendo-nos os problemas mais prementes e atuais de alguns dos meios de obtenção de prova intrusivos na reserva da vida privada e familiar: como a infiltração policial na ordem jurídica espanhola, o cavalo de Troia instalado em sistemas informáticos [v.g., computador, iPhone, smartphone], a recolha de elementos de prova e futura admissibilidade através de processos especiais para-processuais, as interceções de comunicações e respetiva cadeia de custódia de prova, a localização celular, a função do/a Delegado/a de

pela sociedade e pelos intervenientes no processo-crime $a b$ initio ad finem para que haja uma "dupla filtragem: constitucional e convencional, em uma compreensão inserida na complexidade dos fatos, regras e princípios" [cf. GIACOMOLLI, Nereu José. O Devido Processo legal. Abordagem conforme a Constituição Federal e ao Pacto de São José da Costa Rica. São Paulo: Atlas, 2014, p. 214] e, assim, se promova um processo penal democrático assente na legalidade em igualdade - esta como direito e princípio do Direito de um Estado democrático [cf. VIEIRA, Renato Stanziola. Paridade de Armas no Processo Penal. Brasília: Gazeta Jurídica, 2014, pp. 22-39] - e se realize a justiça como manifestação ético-jurídica da dignidade da pessoa humana. 
Polícia segundo um discurso do garantismo e o recurso a redes ou grupos sociais como os constituídos pelo WhatsApp.

O recurso ao agente infiltrado é uma técnica excecional e de ultima et extrema ratio para a repressão criminal no sentido de permitir uma adequada, necessária e razoável descoberta e recolha da prova real e identificação e determinação da prova pessoal de específicos tipos legais de crime. Adán Carrizo González-Castell aborda o agente infiltrado policial na ordem jurídica espanhola no quadro da repressão da corrupção, sendo de destacar o pressuposto político-sociológico da complexidade e das especificidades da corrupção a nível nacional e supranacional que não só legitima o recurso à infiltração policial como impõe uma cooperação judiciária e policial europeia e internacional em matéria penal, que deve respeitar o carácter excecional da restrição de direitos fundamentais e os pressupostos constitucionais de proporcionalidade, de subsidiariedade, de indispensabilidade e de impossibilidade objetiva na obtenção de prova por meio menos gravoso, da autonomia da vontade e integridade pessoal do policial a infiltrar ou infiltrado, quando se opta pela restrição e admissibilidade deste meio oculto de obtenção de prova.

Próximo desta discussão jurídica encontra-se o texto de Francesco Caprioli sobre o captatore informático, conhecido como o cavalo de Troia que se instala no software de vários aparelhos eletrónicos com a finalidade de monitorizar e recolher dados e elementos probatórios, em especial as mensagens e dados de tráfego. Não obstante o Codice di Procedura Penale italiano não prever qualquer dispositivo sobre este meio oculto de obtenção de prova, o texto apresenta-nos um visão da doutrina e da jurisprudência italianas quanto ao âmbito da admissibilidade de meios atípicos de prova - prove non disciplinate dalla legge [art. 189. ${ }^{\circ} \mathrm{CPP}$ italiano] -, e considera que, em determinadas condições e atos de investigação, é admissível o recurso ao captatore informático desde que não esteja em causa ou envolvido um direito fundamental pessoal. Mas deve ser inadmissível se o «cavalo de Troia» envolver ou lesar um concreto direito fundamental pessoal. Francesco Caprioli faz uma análise crítica uma vez que, na linha da teoria alemã, existe um atentado à privacidade da pessoa investigada e um deficit de determinação do paradigma intercetivo, cuja restrição exige uma intervenção 
do legislador de modo a positivar a admissibilidade e os pressupostos materiais e processuais em conformidade com a Constituição italiana.

O perigo da vulgarização do recurso aos meios ocultos de investigação ou de obtenção de prova, em especial das interceções e gravações de conversações, está bem presente no texto que António Santoro, Natália Tavares e Jefferson Gomes nos trazem sobre interceção telefónica e a respetiva cadeia de custódia da prova. Os números apresentados pelos autores demonstram que Ziegler tinha razão quando prognosticava que os polícias de futuro seriam polícias de rato de computador por submissão aos meios tecnológicos. Esta real gravidade investigatória aprofunda-se quando aquelas estão sob o jugo de autorizações judiciais sem uma razoável e mínima fundamentação para intercetar, monitorar e gravar as conversações entre pessoas, colocando em causa princípios estruturantes do processo penal, como o do contraditório, por a informação ser "produzida e submetida à valoração judicial sem influência da defesa que, no máximo, exerce um contraditório diferido ou a posteriori". Discordando dos autores quando consideram que a interceção das comunicações é "um meio de investigação de prova atípico", uma vez que é um dos meios ocultos de investigação que há muito se encontra tipificado nos códigos processuais penais ou nas legislações avulsas processuais penais. Mas deve realçar-se a preocupação dos autores no sentido de submeter o recurso a este meio oculto de investigação a uma metódica científica e jurídica para efetiva tutela dos direitos e liberdades fundamentais de cada cidadão. Metodologia essa que não se deve prender apenas quanto aos pressupostos materiais e processuais de recurso, mas a um controlo quanto à necessidade e finalidade concreta do meio de modo a evitar a "vulgaridade" a que se chegou e a "disciplinar e uniformizar as rotinas visando ao aperfeiçoamento do procedimento de interceptação telefónica", sem que se olvide o sistema de receção e armazenamento de dados e a respetiva cadeia de custódia da prova.

A localização celular de agentes de crimes e de vítimas é outro dos meios ocultos de investigação criminal que deve obediência ao quadro constitucional democrático de cada Estado. Cleopas Santos e Samyr Vale apresentam um texto que trata da importância de um meio tecnológico de investigação de suma relevância para a deteção de vítimas de tráfico de seres humanos, sem que se olvide a necessidade de preservar a reserva da 
privacidade da vida privada e familiar. Nesse sentido, a lei, ao admitir que a polícia criminal recorra a este meio tecnológico sem prévia autorização judicial, parece padecer de inconstitucionalidade material. Os autores discordam das teses de inconstitucionalidade e contrariam-na com base na discussão dos quesitos positivos e operativos da norma, sem que entrem na pura discussão dogmática do princípio do estado de necessidade de intervenção do Estado ou do estado de necessidade justificante que neutraliza a ilegalidade ou a inconstitucionalidade material, uma vez que a vida e a integridade pessoal e a liberdade de uma pessoa [vítima] são valores superiores e merecem tutela efetiva e imediata. Mas, no caso de a pessoa ser o agente de um crime, parece-nos que existe um meio oculto de obtenção de prova pessoal sem prévio controlo judicial, ou seja, sem respeito pelo princípio de reserva de juiz e, por essa razão, ferido de inconstitucionalidade. Estamos perante duas dimensões dinâmicas de intervenção: uma é para salvaguarda da vítima de tráfico de seres humanos, cujo princípio estado de necessidade justificante afasta a desconformidade constitucional, outra é a persecução do agente do crime, cuja conformidade constitucional passará pela prévia autorização judicial.

A função das autoridades policiais criminais - como a função de Delegado de Polícia - é de extrema importância no quadro da prevenção e repressão da criminalidade organizada nacional, regional e transnacional. Mas essa função deve subsumir-se ao garantismo constitucional persecutório de modo a que a dignidade da pessoa humana se assuma como metaprincípio de cada ser humano individualmente considerado e de todos os seres humanos viventes numa comunidade. O texto de Soraia Mendes e de Patrícia Burin tratam deste tema face à liberdade de expressão e da respetiva conflitualidade com as notícias da aplicação de medidas criminais coercitivas da liberdade do cidadão visado com as ações da polícia criminal, e recolocam, de forma subtil, a discussão sobre a dimensão material concreta do estado da presunção de inocência - presunção de não culpabilidade - perante a aplicação de medidas restritivas da liberdade, em especial face à atuação do Delegado ou Delegada de Polícia como responsáveis pelo inquérito policial [investigação preliminar] no Brasil. Acrescentamos que essa dialética exige uma Polícia ao serviço do povo e da democracia, uma Polícia de um Estado de direitos humanos, que não se deixe embrenhar em palmarés de negação dos di- 
reitos e liberdades fundamentais na defesa de meios ocultos de investigação criminal tão-só por serem eficazes no imediato.

A relação entre os meios de que dispõe a ação persecutória perante os meios utilizados pelos grupos organizados criminosos é, sempre, um debate atual e recorrente. A discussão do acesso às redes sociais ou grupos comunicacionais - fontes abertas e fontes fechadas - para deteção, recolha, aquisição e tratamento de provas a serem utilizadas em sede de processo-crime é um debate que se impõe, mas com a respetiva moderação, sob pena de a análise crítica da prova e os métodos de análise informativa da prova se esgotarem no conteúdo das redes ou de plataforma de comunicação. Priscilla Placha Sá aborda a questão do acesso ao conteúdo do WhatsApp trocado e comunicado entre os vários agentes de crimes, em especial os que se encontram nos presídios. Fala-nos de que o planeamento e a ordem das chacinas nos presídios brasileiros foram desenvolvidos com ajuda do WhatsApp instalado nos celulares dos presos, cujas plataformas e redes sociais substituíram os recados e os bilhetes do passado. Mais do que discutir o acesso ao conteúdo exposto nessas redes - fotografias e vídeos compartilhados pela internet, assim como comunicações ordinatórias e diretivas, em pleno presídio -, a Autora coloca a questão da entrada dos celulares e da falta de controlo e monitoramento do uso delituoso das tecnologias da informação no seio das prisões do Brasil. Mas do texto podemos retirar uma questão: o acesso pelas agências de inteligência policial e de Estado a essas redes fechadas de comunicação evitaria as chacinas e a proliferação da criminalidade organizada no interior dos presídios brasileiros ou de outros países do mundo?

Os textos assentam numa tónica central que devemos ter sempre no nosso pensamento jurídico-científico: as investigações preliminares, os meios ocultos de obtenção de prova e as novas tecnologias de comunicação representam uma restrição aos direitos, liberdades e garantias fundamentais pessoais, mas que se impõe como necessária e excecional na persecução de uma criminalidade organizada e estruturada nacional, regional e internacionalmente, e, por essa razão, as restrições inatas e inerentes a tais ações e meios devem, a par de uma rigorosa legislação, ser conformes ao quadro jurídico-constitucional legitimo, válido, vigente e efetivo sob pena de negarmos o Estado constitucional democrático.

Pinhal Novo/Lisboa, 20 a 22 de maio de 2017. 


\section{REFERÊNCIAS}

ANDRADE, Manuel da Costa. "Bruscamente no Verão Passado", a Reforma do Código de processo penal. Observações críticas sobre uma lei que podia e devia ter sido diferente. Coimbra: Coimbra Editora, 2009.

DIAS, Jorge de Figueiredo. Direito Processual Penal. Lições policopiadas por Maria João Antunes. Coimbra, 1988-9.

GIACOMOLLI, Nereu José. O Devido Processo legal. Abordagem conforme a Constituição Federal e ao Pacto de São José da Costa Rica. São Paulo: Atlas, 2014. ROXIN, Claus. Derecho Procesal Penal. Tradução do alemão Strafverfahrensrecht de Gabriela E. Córdoba e Daniel R. Pastor. Buenos Aires: Del Puerto s.r.l., 2000. ROXIN, Claus; ARZT, Günther; TIEDEMANN, Klaus. Introdução ao Direito Penal e ao Direito Processual Penal. Tradução do alemão Einführung in das Strafrecht und Strafprozessrecht de Gercélia Batista de Oliveira Mendes. Belo Horizonte: Del Rey, 2007.

VALENTE, Manuel M. G. Processo penal - Tomo I. 3. ${ }^{\text {a }}$ Edição. Coimbra: Almedina, 2010.

VIEIRA, Renato Stanziola. Paridade de Armas no Processo Penal. Brasília: Gazeta Jurídica, 2014.

\section{COMO CITAR ESTE EDITORIAL:}

VALENTE, Manuel M. G. Editorial dossiê "Investigação preliminar, meios ocultos e novas tecnologias". Revista Brasileira de Direito Processual Penal, Porto Alegre, vol. 3, n. 2, p. 473-482, mai./ago. 2017.

https://doi.org/10.22197/rbdpp.v3i2.82

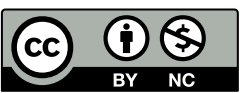

Esta obra está licenciada com uma Licença Creative Commons Atribuição-NãoComercial 4.0 Internacional. 